\title{
Tools of market oriented rail restructuring with special regard to improving management information systems
}

\author{
Katalin Tánczos, DSc \& Zoltán Bokor, PhD
}

\section{Introduction}

The results of long term transport performance and market share analyses show that the role of railway transport has significantly decreased in the past 25 years. This was caused by the structural and behavioural changes in the economy and the inflexible operation of railway companies. According to the results of comparative analyses the observed development tendencies are differentiated by the technology level and operation circumstances of railways.

Practical experiences verify that market orientation in the framework of appropriate regulation can be a successful means to consolidate business processes. This is more and more important in the case of today's railway companies.

The paper aims to discuss the following points:

- identifying a set of tools which make the operation and management of rail companies more effective;

- analysing the strategic planning process of rail companies which helps to find a suitable model for adapting the identified tools;

- selecting the controlling based cost and revenue management for a detailed analysis and evaluating models for applying the methodology for the case of rail transport;

- evaluating a controlling based management system model for rail companies;

- describing the operation processes of the rail controlling information and management system model;

- making recommendations for the practical adaptation of the evaluated models. 


\section{The main tools of market oriented rail transport}

The means of rail market orientation collected on the basis of national and international special literature can be systematised according to defined factor groups. The factors and factor groups aren't independent, so a relation system has to be explored between them to prepare the practical adaptation. The most important rail restructuring factors including their cause-effect relationship are shown in figure 1. National and international transport regulation determines the main frames for rail strategic planning. Rail strategic planning results in marketing and innovation policies (in strong interaction between them). A further important outcome of strategy making is the reorganisation policy of the rail operation and management system. Finally the effective BPR needs to be supported by controlling based cost and revenue and furthermore quality information/management systems.

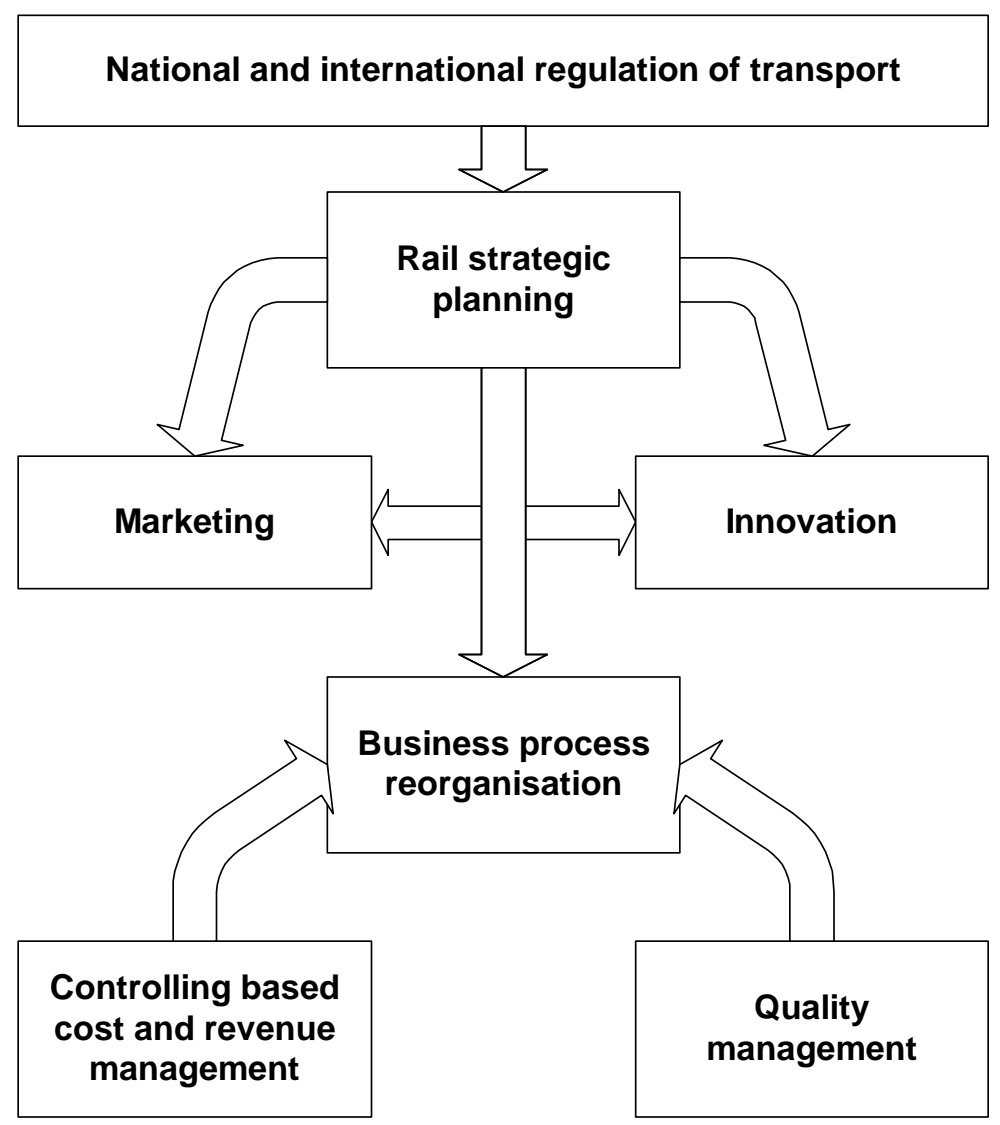

Figure 1: Means of market oriented rail restructuring

The practical use of the identified means can be realised in a framework of a model being suitable for market position of the given railway company. That's why the core of rail restructuring is the strategic planning process. Using the tools of strategic modelling possible development images can be set up along specific dimensions. On the basis of selected relevant images market orientation models for railways can be developed that consist of different combination of the identified factor groups. The models help railway companies to develop a strategy that improves their efficiency and competitiveness. 
Figure 2 illustrates the strategic modelling process for the case of a rail company. The analysis of the extern and intern operation circumstances results in three key performance indicators:

1. intensity and pressure of regulation concerning market orientation - as most important extern influencing factor;

2. general state of development (technical equipment and management practices) and

3. range of operation (structure and geographical extension of rail transport services) - as most important intern influencing factors.

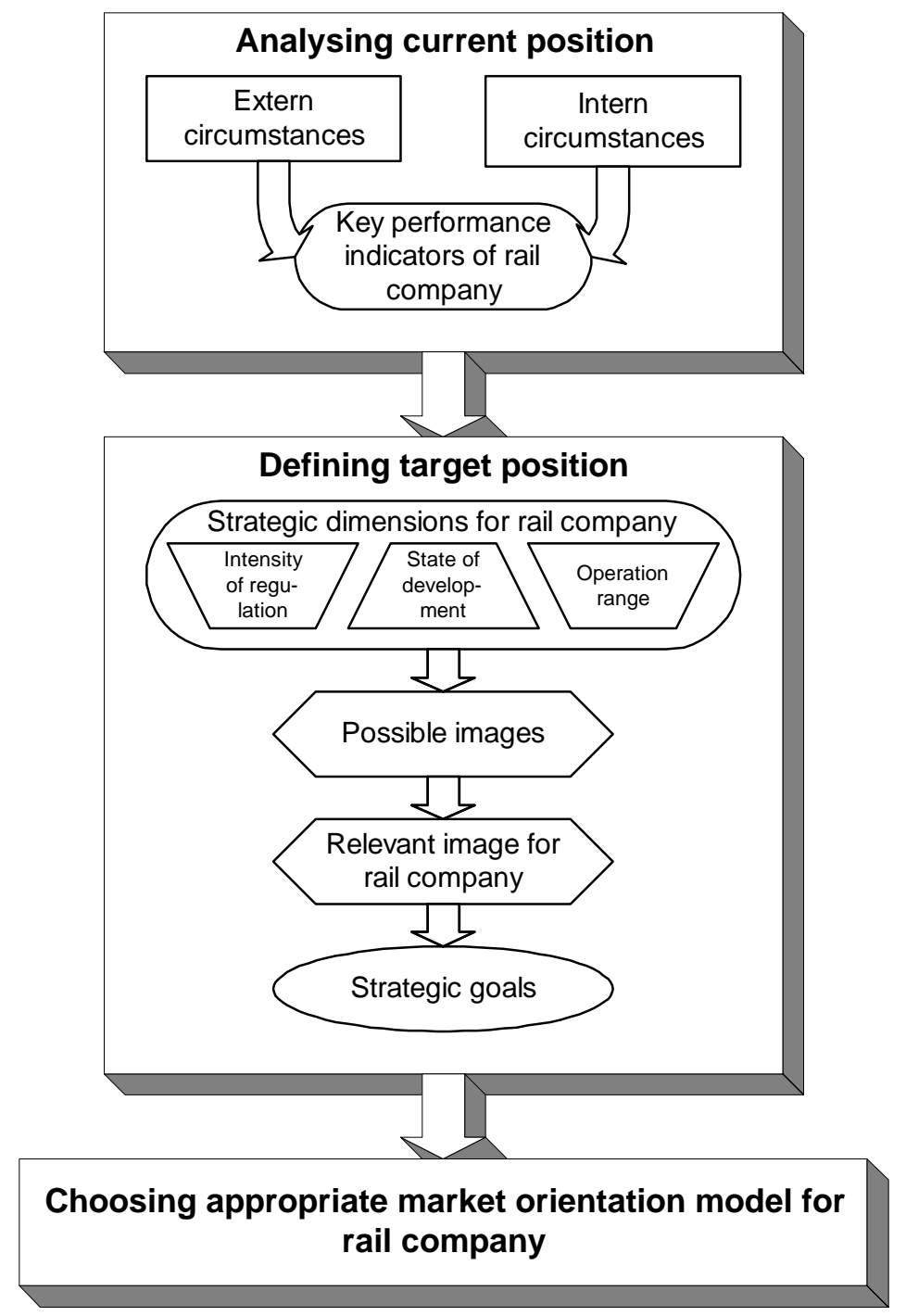

Figure 2: Model of rail strategic planning process

Along these factors - as strategic dimensions - development scenarios for railway companies can be examined. The most relevant scenario points out the strategic goals, which describe the efficient operation form of the given rail transport system. To reach the target position an appropriate restructuring model has to be chosen. The model contains the market orientation tools meeting the requirements of selected strategic directions. 
A suitable rail restructuring model involves the marketing and innovation policy, furthermore the business reorganisation plan. The process of business reorganisation (BPR) has to be supported by building and operating controlling based cost/revenue and quality management systems. Although all the mentioned elements of the restructuring model have a significant role in improving effectiveness of rail systems, this paper pays a special attention to the BPR and the cost/revenue management. 


\section{Business process reorganisation and cost/revenue management by applying controlling based modelling methods}

Effective cost management is one of the most important market orientation tools. Adapting and practical using the latest controlling methods can contribute to the success of rail management: an adequately elaborated controlling system collecting and exploiting relevant information makes operative and strategic planning more reliable. By using such information systems even the implementation of reform strategy can be observed efficiently.

The main phases of building an operative controlling management system are summarised in figure 3. The first task is to identify the tools of operative controlling:

- cost object calculation: examines the costs and performance outputs in business/organisation units;

- intern service calculation: examines the costs of complex services (for instance maintenance) between business/organisation units;

- profit object calculation: examines the cost covering and profit rates of products (for instance rail passenger or cargo transport tasks).

To prepare the practical implementation of controlling based management methods for the case of railway companies models based on domestic circumstances have to be elaborated, moreover an appropriate organisation structure and the acceptability of new procedures has to be ensured. A further task is to assess the informatic supporting possibilities (hardware and software).

When modelling the management structure the basic system elements (objects) are defined, then the performance connections existing between them are identified and finally the data structure and the main structural or functional data concentration areas are built up. The dynamic operation model based on system model describes the management activities planning, accounting, analysis and decision making - using mathematical functions. The continuous business process reengineering influences the structure and operation of the controlling model, but its basic organising principles don't have to be changed. The developed controlling model has to be able to handle the consequences of structural changes to ensure long term applicability. 


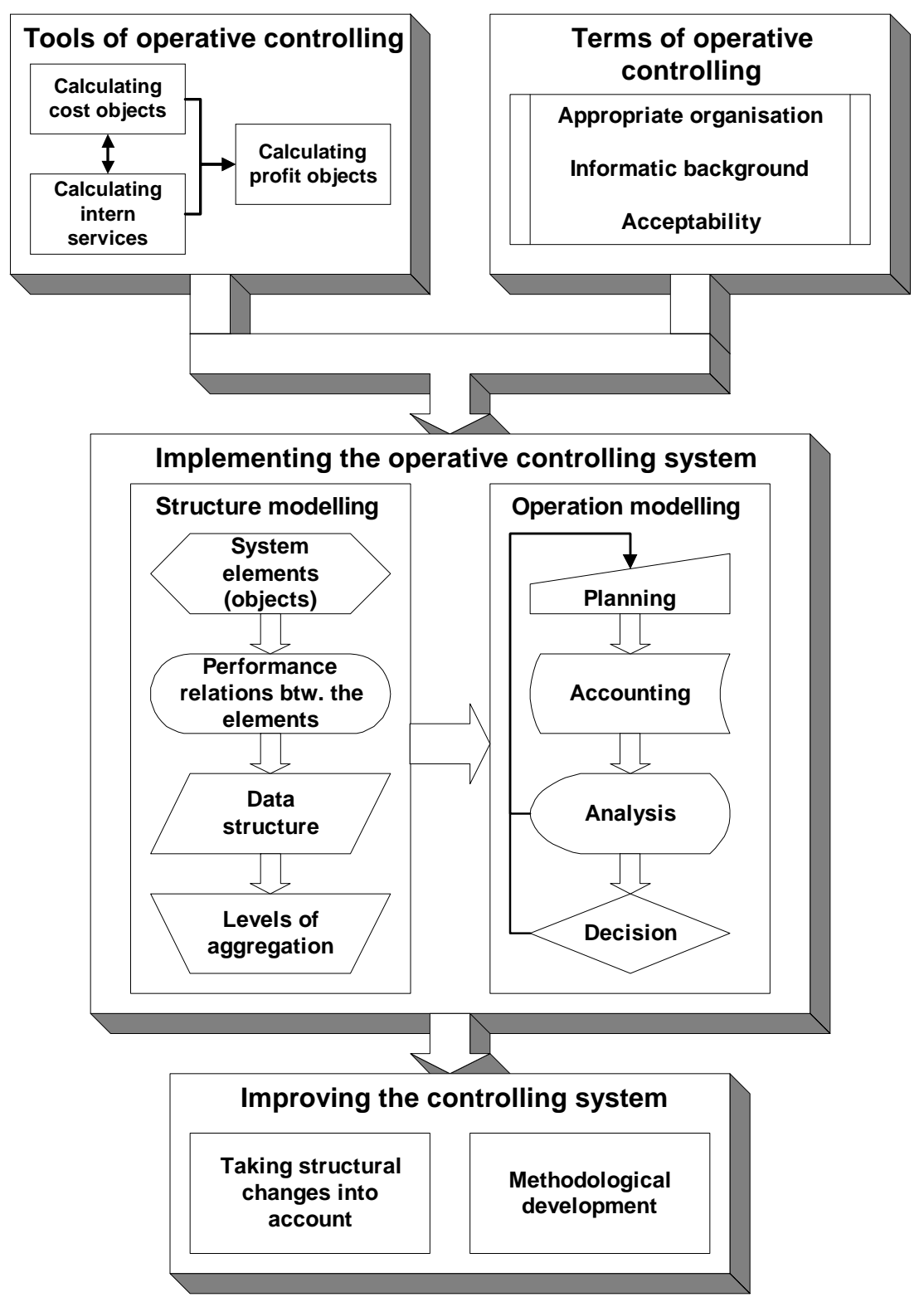

Figure 3: Phases of building the operative controlling management system

A possible controlling system model of the reorganised business operation structure of a market oriented rail (holding) company can be examined in figure 4. The main business processes according to the new rail operation model are the following:

- The two business branches operating in the transport market are the rail passenger and cargo transport units. Their products (profit objects): transporting passengers and goods. Producing these products is the task of commercial, traffic organisation and vehicle (coach or wagon) management units (cost objects). The two rail transport branches use the services of traction and infrastructure companies.

- The infrastructure management branch produces rail track services (profit objects): provides track (including traffic control) and marshalling to rail transport companies. Partly infrastructure maintenance units, partly central and local traffic control units (cost objects) take part in providing these services. 


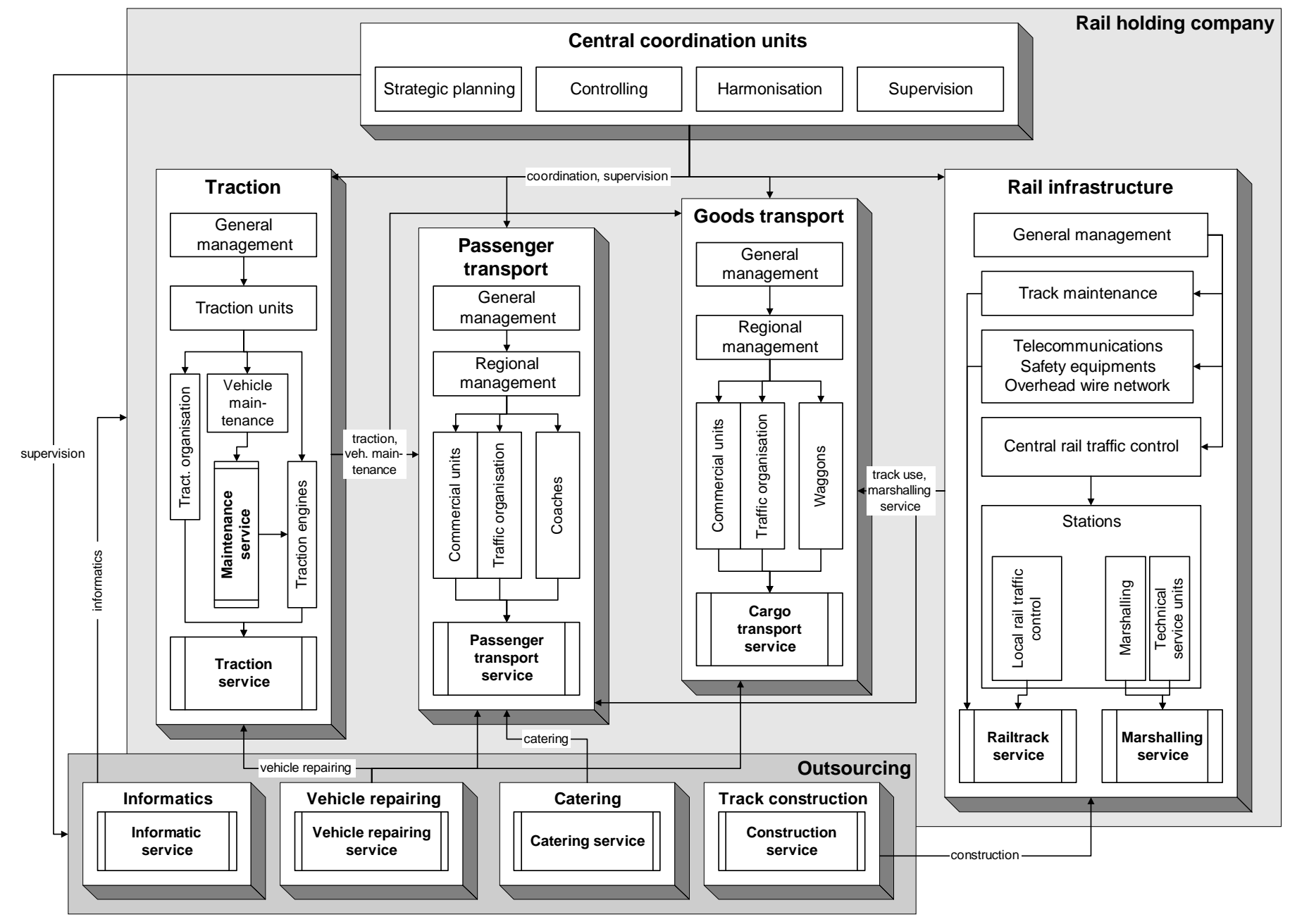

Figure 4: Controlling system model for a reorganised rail company 
- The traction branch provides traction and vehicle maintenance services to rail transport companies (profit objects). Maintenance is done for engines too. Traction processes are carried out by traction organisation, and engine management units (cost objects). Maintenance projects are produced by vehicle maintenance units (cost objects).

- It is reasonable for a rail holding company to outsource some activities, which don't belong to its main activities. These "background" units provide such services like information management, vehicle repairing, track construction or catering.

- The central co-ordination units (cost objects) supervise the operation of the self-managing branches. They define strategic development directions, operate company-wide controlling information systems, co-ordinate business and technological interactions between the branches and supervise safety.

- It is also important to establish an organisation unit for the fair and effective division of track capacity (not showed on the figure). This organisation unit can operate as a part of the infrastructure branch or the central units. The main point is that it have to divide capacity in an independent way, not giving special preference to any rail transport company. A further task is to develop and use an infrastructure charging system based on the results of (controlling aided) cost covering calculation and the consideration of other economic factors like increasing market share.

The management system of the Hungarian state railway company (MÁV) has been changed significantly since 1994, and it moves towards the business operation system described before. The main points of restructuring were the following:

- the state owned company has been converted to an independently operating business company, the main shareholder is henceforward the state;

- the accounting systems of rail operation and rail infrastructure has been separated;

- the main activity areas operate as partly independent branches within the company;

- integrated transactional information systems for rail technology and financial/accounting management have been implemented;

- regional marketing offices have been set up to increase sales in rail personal and goods transport.

Further restructuring plans are the next issues:

- separating the organisations of rail operation and rail infrastructure;

- establishing a rail track capacity divider unit as a part of the rail infrastructure company;

- improving the rail infrastructure pricing system based on marginal user costs;

- forming a rail holding in the long run. 


\section{Operation of developed management information system}

The operation phases/activities of controlling based management information system are shown in figure 5. The first phase is planning. Planning is based on the so-called meta database, which contains the controlling system models and technological data about activities carrying out in the railway system. The cost, performance and revenue plans are produced according to cost and profit objects, then the plan data are made available to the calculation procedures.

The next step is preparing the actual data for the calculation. After collecting basic data they will be mostly processed to meet the requirements of controlling model standards.

When calculating cost objects the elementary intern services/performances has to be priced, which makes it possible to drive the performance based operation costs (so-called secondary costs $=$ costs of intern services) between cost objects. Cost objects can be evaluated by collecting primary costs, driving secondary costs and measuring performance. Further task is aggregating data of cost objects to evaluate operation cost and performance efficiency of bigger business/organisation units as well.

The cost side of the profit objects consists of direct product costs, and direct operation costs driven from cost objects (in performance based way). After adding also the revenue side, it will be possible to evaluate direct cost covering of profit objects. The indirect operation costs are included on aggregated levels of profit objects, which makes it possible to calculate profits of main activity areas. 


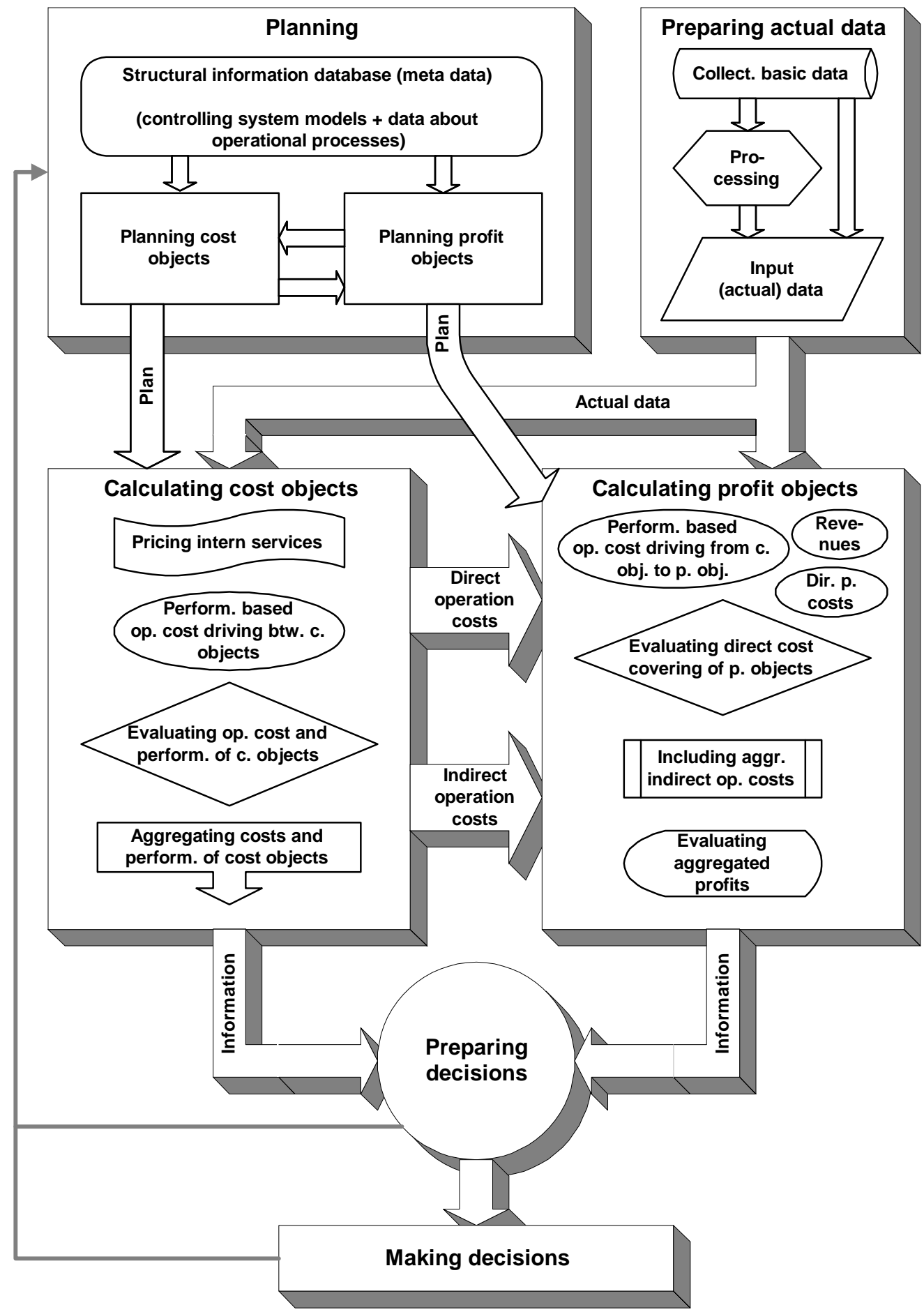

Figure 5: Operation model of the controlling based management information system 


\section{Conclusion}

The management practices of most railway companies don't meet the requirements of market oriented business organisation yet. They have mostly centralised management and information systems, which don't pay enough attention to identify the real operation costs, performances, revenues and profits of rail services.

The management of rail companies can be gradually improved by adapting the proposed models and methods. The practical use of (at least partly) decentralised controlling management systems makes the management activities more treatable and improves the establishment of decisions. The operation costs and performances of different structural units (for instance commercial, rail traffic organisation or control units), and the efficiency of intern services (such as maintenance) became to be analysable. Furthermore the profitability of different products/activities (e.g. passenger or cargo transport tasks) became to be identifiable exactly. On the basis of former information it can be stated among others what rationalisation measures have to be done, which extern service activities should be preferred or which intern services should be replaced.

That is why it is recommendable to reorganise the organisation structure and to develop controlling based management information systems for rail companies. The proposed steps to build such systems are the following:

1. forming a new organisation structure suitable for decentralised management and at the same time for national specific characteristics;

2. determining the cost and profit objects for rail company;

3. determining the performance flows between the cost and revenue objects;

4. evaluating a controlling system model for rail company (based on the object structure and performance flow determined before);

5. describing the cost and profit calculation processes for controlling operation model;

6. implementing the developed controlling system and operation models by applying appropriate business intelligence tools (= software with controlling functionality);

7. organising data flows and evaluating reporting facilities for controlling based rail management system;

8. training the user staff of controlling system.

As a demerit of decentralised rail management systems can be mentioned the increasing coordination demand of the (at least partly) indåpendent operatiîg rail branchesn The solution to this problem ió an integrated management information system wiôh strong informatic bacëground.

Finally, it is to be consideråd that óome developing tasks, like improving interoperaâility oò cost eæfectiveîess areàcommon in the case of South-eastern European railways. But therå are alóo special national charácteristécs, like customår habits, tradiôional pòactices`or geogòaphicalàposition, which have to `be taken into aãcount wèen evaluating operation and management models. 


\section{References}

[1] Bokor, Z: Elaboration and practical use of the conditions of market oriented railway transport with special regard to the controlling based management system

$\mathrm{PhD}$ dissertation, BUTE, 2000

[2] Bokor, Z.: Applying controlling management methods in transport I-II.

Transport Science Review, 1999/10 p. and 1999/12

[3] Tánczos, $K$.: Conditions of efficient operation of integrated transport infrastructure DSc dissertation, Hungarian Academy of Sciences, 1999

[4] Bokor, Z: Methods for cost and revenue management of intern logistic processes in transport companies

Logistic Review, 1999/3

[5] Tánczos, K. - Bokor, Z: Methods for efficient development and maintenance of transport infrastructure

17. Symposium on Transport Science, TU Dresden, 1998

[6] Bokor, Z: Tools of market orientation in railway transport

Management Science Review, 1998/6

[7] Tánczos, $K$.: Conditions of interoperability in rail transport system

Transport Science Review, 1998/3

[8] John Preston: Railway reforment repreneurship: a tale of three countries PTRC European Transport Conference, Proceedings of Seminar G, 1998

[9] Wissenschaftlicher Beirat: Bahnstrukturreform in Deutschland - Empfehlungen zur weiteren Entwicklung

Internationales Verkehrswesen 12/97, 1997

[10] C. Nash - J. Preston - J. Shires - M. Wardman: Rail Privatisation: The Practice Working Paper 420, Institute for Transport Studies, University of Leeds, 1994 